\title{
Mapping aboveground biomass by integrating geospatial and forest inventory data through a $k$-nearest neighbor strategy in North Central Mexico
}

\author{
Carlos A AGUIRRE-SALADO ${ }^{1,2 *}$, Eduardo J TREVIÑO-GARZA ${ }^{1}$, Oscar A AGUIRRE-CALDERÓN ${ }^{1}$, \\ Javier JIMÉNEZ-PÉREZ ${ }^{1}$, Marco A GONZÁLEZ-TAGLE ${ }^{1}$, José R VALDÉZ-LAZALDE ${ }^{3}$, Guillermo \\ SÁNCHEZ-DÍAZ ${ }^{2}$, Reija HAAPANEN ${ }^{4}$, Alejandro I AGUIRRE-SALADO ${ }^{3}$, Liliana MIRANDA-ARAGÓN ${ }^{5}$ \\ ${ }^{1}$ Faculty of Forest Sciences, Autonomous University of Nuevo Leon, Linares 67700, Mexico; \\ ${ }^{2}$ Faculty of Engineering, Autonomous University of San Luis Potosi, San Luis Potosí 78290, Mexico; \\ ${ }^{3}$ Forestry Program, Postgraduate College, Montecillo 56230, Mexico; \\ ${ }^{4}$ Haapanen Forest Consulting, Kärjenkoskentie 64810, Finland; \\ ${ }^{5}$ Faculty of Agronomy and Veterinary, Autonomous University of San Luis Potosí, San Luis Potosí 78321, Mexico
}

\begin{abstract}
As climate change negotiations progress, monitoring biomass and carbon stocks is becoming an important part of the current forest research. Therefore, national governments are interested in developing forest-monitoring strategies using geospatial technology. Among statistical methods for mapping biomass, there is a nonparametric approach called $k$-nearest neighbor $(k N N)$. We compared four variations of distance metrics of the $k \mathrm{NN}$ for the spatially-explicit estimation of aboveground biomass in a portion of the Mexican north border of the intertropical zone. Satellite derived, climatic, and topographic predictor variables were combined with the Mexican National Forest Inventory (NFI) data to accomplish the purpose. Performance of distance metrics applied into the $k N N$ algorithm was evaluated using a cross validation leave-one-out technique. The results indicate that the Most Similar Neighbor (MSN) approach maximizes the correlation between predictor and response variables $(r=0.9)$. Our results are in agreement with those reported in the literature. These findings confirm the predictive potential of the MSN approach for mapping forest variables at pixel level under the policy of Reducing Emission from Deforestation and Forest Degradation (REDD+).
\end{abstract}

Keywords: $k$-nearest neighbor; Mahalanobis; most similar neighbor; MODIS BRDF-adjusted reflectance; forest inventory; the policy of Reducing Emission from Deforestation and Forest Degradation

Citation: Carlos A AGUIRRE-SALADO, Eduardo J TREVIÑO-GARZA, Oscar A AGUIRRE-CALDERÓN, Javier JIMÉNEZ-PÉREZ, Marco A GONZÁLEZ-TAGLE, José R VALDÉZ-LAZALDE, Guillermo SÁNCHEZ-DÍAZ, Reija HAAPANEN, Alejandro I AGUIRRE-SALADO, Liliana MIRANDA-ARAGÓN. 2014. Mapping aboveground biomass by integrating geospatial and forest inventory data through a $k$-nearest neighbor strategy in North Central Mexico. Journal of Arid Land, 6(1): 80-96. doi: 10.1007/s40333-013-0191-x

The United Nations Framework Convention on Climate Change proposes the possibility of introducing a compensation scheme for Reducing Emissions from Deforestation and Forest Degradation (REDD+) after the Kyoto Protocol. Because approximately $18 \%$ of greenhouse gas emissions can be attributed to deforestation, the maintaining of forests has gained attention as one of the main options to climate change mitigation efforts (Streck et al., 2008; Köhl et al., 2009).

Countries interested in benefiting from REDD+ incentives must develop their own systems to measure, report, and verify (MRV) forest biomass/carbon stocks in a consistent, comparable and complete way. An MRV system will serve to transparently monitor car-

*Corresponding author: Carlos A AGUIRRE-SALADO (E-mail: carlos.aguirre@uaslp.mx)

Received 2012-11-19; revised 2013-01-14; accepted 2013-03-18

(C) Xinjiang Institute of Ecology and Geography, Chinese Academy of Sciences, Science Press and Springer-Verlag Berlin Heidelberg 2013 
bon stocks and to encourage those countries that wish to make economic investments to offset or neutralize their emissions of greenhouse gases under the REDD+ initiative (FAO, 2009).

Proper integration of a monitoring system for REDD+ requires the complementary use of different methods. The initial phase involves fitting allometric models at the genus or species level to estimate the individual tree biomass/carbon stocks relationship using both diameter and tree height. Fortunately, there is already a considerable set of allometric models in the scientific literature for transforming the individual tree volume $\left(\mathrm{m}^{3}\right)$ into biomass $(\mathrm{Mg})$ or carbon $(\mathrm{Mg})$ values, or for estimating it directly from tree diameter and height (Návar, 2009). To map the biomass/carbon stocks over large areas, there are two general methods defined by the spatial information source: 1) vector maps or 2) remotely- sensed data.

The first method requires vegetation and land use maps that have area estimates by land cover polygon. Forest biomass/carbon stocks estimates on a per hectare basis are averaged $\left(\mathrm{Mg} / \mathrm{hm}^{2}\right)$ for each land cover polygon and then multiplied by the total area of each polygon to obtain generalized estimates of biomass/carbon stocks. De Jong et al. (2010) used such an approach for estimating greenhouse gas emissions from land use changes in Mexico (1993-2002) and the values were reported as part of the $4^{\text {th }}$ Mexican National Communication to UNFCCC (SEMARNATINE, 2009). This method was considered a valid procedure for monitoring and reporting anthropogenic emissions of greenhouse gases and was revised at the Conference of Parts (COP16) held in Cancun, Mexico (GOFC-GOLD, 2010). Other countries such as India (Kaul et al., 2009) and Uganda (Nakakaawa et al., 2011) have also successfully used this methodology to estimate carbon fluxes in their ecosystems.

The second method for estimating biomass/carbon stocks, implemented in this paper, has been used by countries with a history of using digital satellite imagery data. Quantitative and qualitative variables (Y response variables) gathered in forest inventories are, to a certain extent, statistically related to remotelysensed data (X predictor variables). This approach benefits from the use of multivariate data that better captures the spatial variability of field conditions and permits estimation at pixel level. There are reports in recent literature, such as Blackard et al. (2008) in the USA, Anaya et al. (2009) in Colombia, and Gallaun et al. (2009) in Europe, which support the use of this methodology for carrying out forest aboveground biomass estimations at large spatial extents, but are also quite detailed pixel by pixel. The above stated highlights the importance of directly using spectral data from satellite imagery when building an MRV system in any country (De Leeuw et al., 2010) and is the main motivation for this study.

A nonparametric algorithm called the $k$-nearest neighbor $(k \mathrm{NN})$ has been widely used for estimating forest density using satellite imagery (Tomppo et al., 2008; McRoberts, 2012). This approach has advantages over parametric models because it represents a dynamic way to estimate forest density, quasi-unique for each pixel, making it a powerful method (Chirici et al., 2008; McRoberts, 2008). Applications of the $k \mathrm{NN}$ algorithm include estimation of wood volume (Baffeta et al., 2009; McRoberts, 2009), biomass (Breidenbach et al., 2012), carbon (Aguirre-Salado et al., 2009; Fuchs et al., 2009), tree species composition (Gjertsen, 2007), and vegetation types (Zhou et al., 2008), among others.

The overall objective of this paper is to present a methodology to spatially estimate aboveground biomass by implementing a $k \mathrm{NN}$ modeling strategy for the state of San Luis Potosí, Mexico as a basis for the design of an MRV system at the state level to support international processes, i.e. REDD+. This was carried out by the following particular objectives: 1) to determine the significant predictor variables (satellite based, climatic, and topographic) for estimating aboveground biomass; 2) to compare the performance of four multivariate distance metrics into the $k \mathrm{NN}$ approach; 3) to map aboveground forest biomass with both selected distance metric into the $k \mathrm{NN}$ approach and predictor variables; and 4) to compare the estimates with reported studies.

\section{Study area and data analysis}

\subsection{Study area}

The study area is located at the northern border of the 
Tropic of Cancer in the Mexican state of San Luis Potosi. It is situated between $21^{\circ} 07^{\prime} \mathrm{N}-24^{\circ} 22^{\prime} \mathrm{N}$ and $98^{\circ} 20^{\prime} \mathrm{W}-102^{\circ} 17^{\prime} \mathrm{W}$ and covers $6.1 \times 10^{6} \mathrm{hm}^{2}$. San Luis Potosi has a range of ecosystems and landscape compositions that can be classified into four biogeographical zones: Altiplano, Centro, Media and Huasteca (Fig. 1a). More than $75 \%$ of the study area (including Altiplano, Centro and Media zones) presents arid and semi-arid climates. Figure $1 \mathrm{~b}$ describes

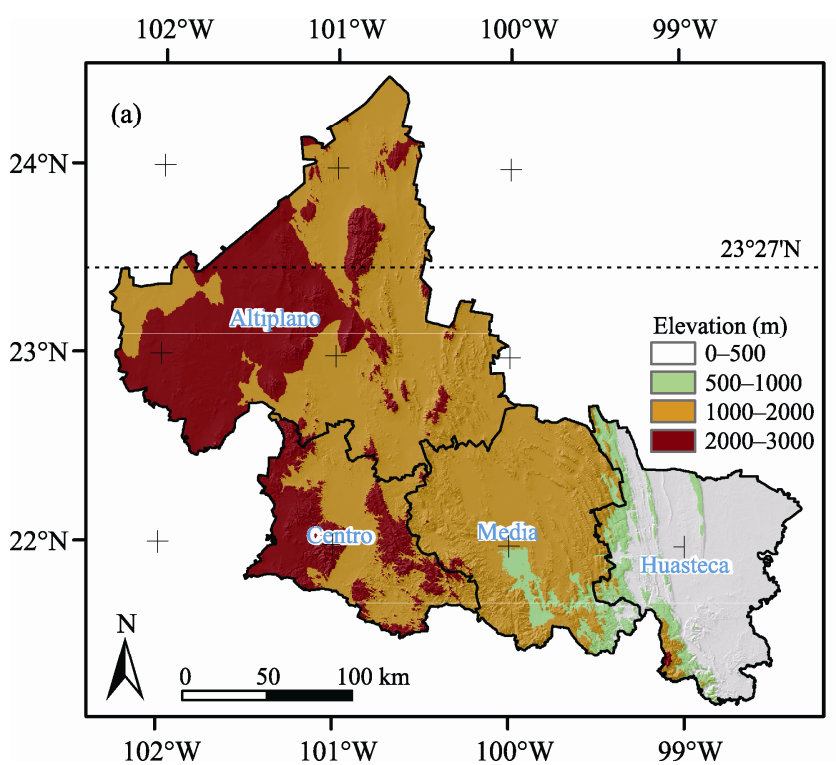

the spatial variability of mean annual precipitation (MAP) over the entire study area. Orange-colored circles represent weather stations in zones with arid and semi-arid climates. The variability between climate types is mainly due to mountain formations, winds coming from the Gulf of Mexico, and an inverse relationship between temperature and altitude present at these geographical latitudes (Miranda-Aragón et al., 2012).

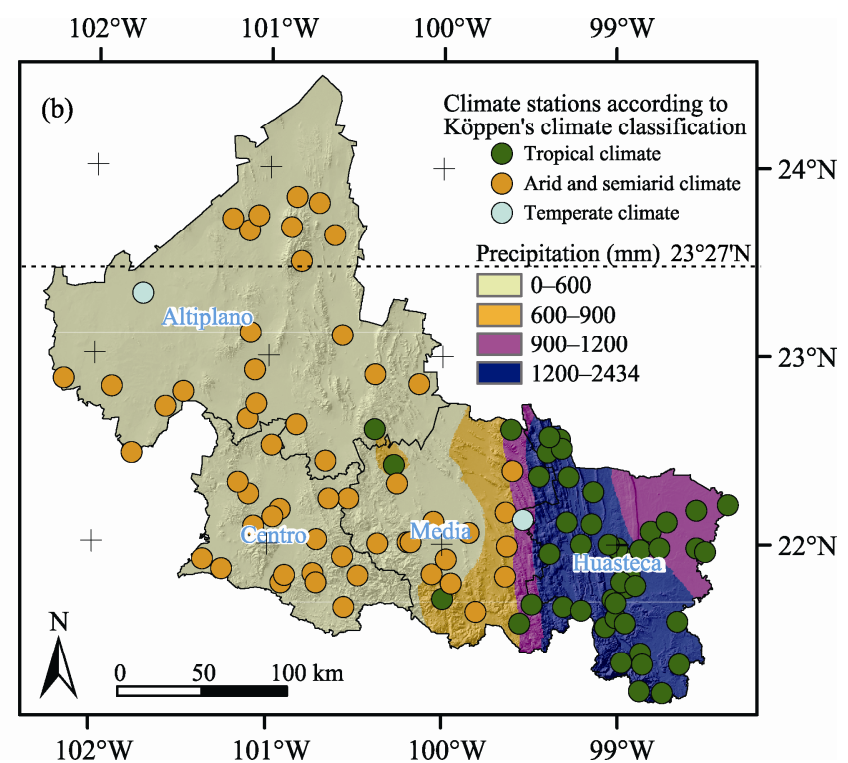

Fig. 1 The study area of San Luis Potosi, Mexico. (a) Topographic map including Tropic of Cancer $\left(23^{\circ} 27^{\prime} \mathrm{N}\right)$, i.e. upper border of intertropical zone; (b) Precipitation map including climatic zones.

\subsection{Forest inventory data}

The current national forest inventory of Mexico consists of a network of nearly 25,000 permanent sampling clusters re-measured during the period of 2005-2007. Distance between sampling clusters varies from $5 \mathrm{~km}$ for temperate/tropical forests to $20 \mathrm{~km}$ for arid lands. Each cluster contains four sampling plots $\left(400 \mathrm{~m}^{2}\right)$, totaling an area of $1,600 \mathrm{~m}^{2}$ (GOFC-GOLD, 2010; National Forestry Commission of Mexico, 2010). The data gathered include diameter at breast height (DBH) of $1.3 \mathrm{~m}$ above tree base, tree height $(\mathrm{TH})$, and species name. Further description of the Mexican national forest inventory can be found in Colditz et al. (2012). After a quality analysis of data that consisted of detecting and eliminating incomplete sampling clusters (i.e. with less than four sampling plots), we selected 235 sampling clusters from the
National Forest Inventory (NFI) database collected in the state of San Luis Potosi (Fig. 2). Coordinates of

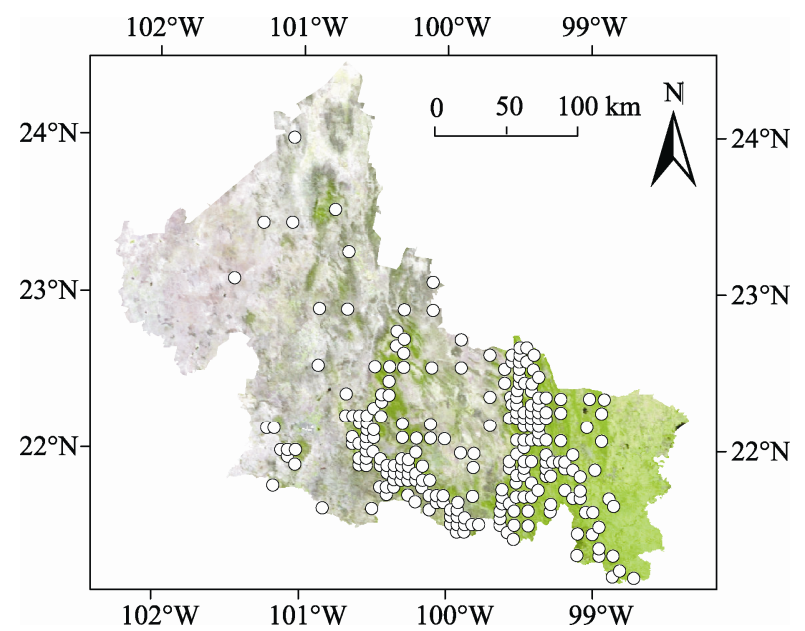

Fig. 2 Spatial distribution of the sampling clusters in San Luis Potosi, Mexico selected from National Forest Inventory database 
the sampling plots were re-projected from Plate-Carrée to the Universal Transverse Mercator coordinate system, datum World Geodetic System 1984. To calculate the individual tree aboveground biomass for each of the 364 species reported in the NFI database, we used 25 different models reported by Návar (2009) (Table 1). The mathematical forms of the models vary from linear to exponential. Several authors constructed such models with data gathered from destructive measurements of a number of trees or shrubs covering the full spectrum of age, i.e. diameter sizes (Table 1). All models employed DBH $(\mathrm{cm})$ and TH $(\mathrm{m})$ to estimate individual tree total biomass $(\mathrm{kg})$. Individual tree aboveground biomass values (Y response variables) were summarized for each plot and an expansion factor of 6.25 was applied to get per hectare estimates. Data processing was carried out using the SAS software (SAS Institute Inc., 2004).

\subsection{Satellite data}

The Moderate Resolution Imaging Spectroradiometer (MODIS) BRDF-adjusted reflectance product (MCD43A4) was used. It has a moderate spatial resolution $(500 \mathrm{~m} \times 500 \mathrm{~m})$ and very high radiometric quality data (NASA, 2009). This was important, as we wanted to have a seamless imagery product that covered the whole study area. High spatial resolution data such as Landsat or SPOT were of limited use, as the available imagery was taken in different periods of

Table 1 Allometric models used to estimate aboveground biomass in the study area (cited from Návar, 2009)

\begin{tabular}{|c|c|c|c|}
\hline Number & Model & $\mathrm{N}$ & Reference \\
\hline 1 & $\mathrm{AGB}=-0.43154+0.011037 \times\left(\left(\mathrm{DBH}^{\wedge} 2\right) \times \mathrm{TH}\right)+0.113602 \times \mathrm{DBH}+0.307809 \times(\ln (\mathrm{DBH}))$ & 913 & Návar et al. (2004) \\
\hline 2 & $\mathrm{AGB}=-4.4576+1.4946 \times \mathrm{DBH}$ & 18 & Návar et al. (2004) \\
\hline 3 & $\mathrm{AGB}=0.5772+0.011244 \times\left(\mathrm{DBH}^{\wedge} 2\right) \times(\mathrm{TH})$ & 78 & Návar et al. (2004) \\
\hline 4 & $\mathrm{AGB}=0.08952 \times\left(\mathrm{DBH}^{\wedge} 2.33\right)$ & 10 & Etchevers-Barra et al. (2002) \\
\hline 5 & $\mathrm{AGB}=-3.72131+0.248698 \times \mathrm{DBH}+5.1932 \times \mathrm{TH}-10.4555 \times(\ln (\mathrm{TH}))$ & 52 & Návar et al. (2004) \\
\hline 6 & $\mathrm{AGB}=\left(\mathrm{EXP}\left(0.0336 \times\left(\ln \left(\left(\mathrm{DBH}^{\wedge} 2\right) \times \mathrm{TH}\right)\right)\right)\right)$ & 17 & Cairns et al. (2003) \\
\hline 7 & $\mathrm{AGB}=0.2365 \times\left(\mathrm{DBH}^{\wedge} 2.1928\right)$ & 30 & Sampaio and Silva (2005) \\
\hline 8 & $\begin{array}{l}\mathrm{AGB}=\left((0.0013 \times(\mathrm{DBH} \times \mathrm{DBH} \times \mathrm{TH}))^{\wedge}(0.9218)\right)+\left((0.0072 \times(\mathrm{DBH} \times \mathrm{DBH} \times \mathrm{TH}))^{\wedge}(1.0451)\right) \\
+\left((0.0029 \times(\mathrm{DBH} \times \mathrm{DBH} \times \mathrm{TH}))^{\wedge}(1.0172)\right)+\left((0.0010 \times(\mathrm{DBH} \times \mathrm{DBH} \times \mathrm{TH}))^{\wedge}(0.8038)\right) \\
+\left((0.0893 \times(\mathrm{DBH} \times \mathrm{DBH} \times \mathrm{TH}))^{\wedge}(0.5326)\right)\end{array}$ & 125 & Cole and Ewel (2006) \\
\hline 9 & $\mathrm{AGB}=(\mathrm{EXP}(1.021 \times(-3.323+(1.914 \times(\ln (\mathrm{DBH}))))))$ & 36 & Northup et al. (2005) \\
\hline 10 & $\mathrm{AGB}=(\mathrm{EXP}(-0.834+2.223 \times \ln (\mathrm{DBH})))$ & 161 & Segura et al. (2006) \\
\hline 11 & $\mathrm{AGB}=\left(0.3569 \times\left(\mathrm{DBH}^{\wedge} 1.8565\right)\right)$ & 30 & Sampaio and Silva (2005) \\
\hline 12 & $A G B=0.937974+0.0126 \times\left(\left(\mathrm{DBH}^{\wedge} 2\right) \times \mathrm{TH}\right)$ & 63 & Návar et al. (2004) \\
\hline 13 & $\mathrm{AGB}=\mathrm{EXP}\left(0.46+0.037 \times\left(\ln \left(\left(\mathrm{DBH}^{\wedge} 2 \times\right) \mathrm{TH}\right)\right)\right)$ & 7 & Cairns et al. (2003) \\
\hline 14 & $\mathrm{AGB}=-0.10528+1.061613 \times \mathrm{DBH}-2.68152 \times(\ln (\mathrm{DBH}))$ & 29 & Návar et al. (2004) \\
\hline 15 & $\mathrm{AGB}=0.1116 \times\left(\mathrm{DBH}^{\wedge} 2.412\right)$ & 30 & Etchevers-Barra et al. (2002) \\
\hline 16 & $\mathrm{AGB}=0.089 \times\left(\mathrm{DBH}^{\wedge} 2.5226\right)$ & 30 & Návar (2008) \\
\hline 17 & $\mathrm{AGB}=0.3460 \times\left(\mathrm{DBH}^{\wedge} 2.0231\right)$ & 30 & Sampaio and Silva (2005) \\
\hline 18 & $\mathrm{AGB}=0.3127 \times\left(\mathrm{DBH}^{\wedge} 2.1183\right)$ & 30 & Sampaio and Silva (2005) \\
\hline 19 & $\mathrm{AGB}=\left(\mathrm{EXP}\left(0.3627+0.0322 \times\left(\ln \left(\left(\mathrm{DBH}^{\wedge} 2\right) \times \mathrm{H}\right)\right)\right)\right)$ & 64 & Cairns et al. (2003) \\
\hline 20 & $\mathrm{AGB}=-0.58367+0.004255 \times\left(\left(\mathrm{DBH}^{\wedge} 2\right) \times \mathrm{H}\right)+0.393071 \times(\mathrm{DBH})$ & 123 & Návar et al. (2004) \\
\hline 21 & $\left.\mathrm{AGB}=\left(\mathrm{EXP}\left(0.0358 \times \ln \left(\left(\mathrm{D}^{\wedge} 2\right) \times \mathrm{H}\right)\right)\right)\right)$ & 11 & Cairns et al. (2003) \\
\hline 22 & $\mathrm{AGB}=-2.04254+0.387649 \times(\mathrm{DBH})+0.5166 \times(\mathrm{TH})$ & 38 & Návar et al. (2004) \\
\hline 23 & $\mathrm{AGB}=-0.62634+0.001711 \times\left(\left(\mathrm{DBH}^{\wedge} 2\right) \times \mathrm{TH}\right)+0.313902 \times \mathrm{DBH}$ & 29 & Návar et al. (2004) \\
\hline 24 & $\mathrm{AGB}=-2.083+2.536 \times \ln (\mathrm{DBH})$ & 10 & Salis et al. (2006) \\
\hline 25 & $\mathrm{AGB}=0.1371 \times\left(\mathrm{DN}^{\wedge} 2.26\right)$ & 6 & Etchevers-Barra et al. (2002) \\
\hline
\end{tabular}

Note: AGB is the aboveground biomass $(\mathrm{kg})$; DBH is the diameter at breast height $(\mathrm{cm})$; TH is the tree height $(\mathrm{m})$; ln is the natural logarithm; EXP is the mathematical constant (e); $\wedge$ and $\times$ are symbols to indicate exponentiation $\left(\mathrm{a}^{\mathrm{n}}\right)$ and multiplication, respectively; $\mathrm{N}$ is the number of trees or shrubs used to construct the statistical model taken from Návar (2009). 
time (dry and wet seasons), causing poor radiometric coherence between scenes, and complicated any further use. The MCD43A4 spectral dataset is a product built with both Aqua and Terra satellite data, and it is adequate for mapping large areas $\left(>1 \times 10^{6} \mathrm{hm}^{2}\right)$ with an appropriate detail level at the regional scale (Gallaun et al., 2009; Galvao et al., 2011). It contains reflectance values $(\rho)$ at seven different wavelength ranges $(\lambda) ; \rho_{\lambda}$ is adjusted to nadir by a bidirectional distribution function (NBAR). MCD43A4 combines data taken over periods of 16 days to minimize the presence of clouds and is atmospherically corrected. The order of spectral bands is not in accordance with wavelength and was stated by the data producer (Table 2) (NASA, 2009; Bhaduri et al., 2010).

We used MCD43A4 data from the period of 11-26 February 2006 (Julian day 42 to 57). The data were reprojected to the Universal Transverse Mercator projection and coordinate system (UTM-14N). A normalized vegetation index called $\mathrm{NDVI}_{62}$ was calculated as (Aguirre-Salado et al., 2009):

$$
\mathrm{NDVI}_{62}=\left(\rho_{6}-\rho_{2}\right) /\left(\rho_{6}+\rho_{2}\right) \text {. }
$$

This spectral index is sensitive to moisture stress of vegetation and inversely correlated with vegetation biomass. We put emphasis on using this vegetation index because there was some evidence that it worked better when modeling forest biomass with near and middle-shortwave infrared spectral bands (Rock et al., 1986; Gjertsen, 2007; Fuchs et al., 2009; Canisius et al., 2010). A vegetation index that is equivalent to $\mathrm{NDVI}_{62}$ is the normalized difference water index (NDWI), which is constructed similarly to $\mathrm{NDVI}_{62}$ but with the reverse order for numerator elements $\left(\rho_{2}-\rho_{6}\right)$. NDWI can be inversely interpreted as a measure of canopy water content; therefore it is positively correlated with vegetation density (Gao, 1996; Barati et al., 2011).

Another MODIS product used is the vegetation continuous field (VCF), version 3, collection 3 (searchable with the key MOD44B). The MODIS VCF data is a global product constructed using a regression tree-based algorithm. This approach can be used without statistical assumptions on data and handle the complex richness of spectral signatures that exist on the globe. The variable of interest in the model is the percent coverage of tree, herbaceous and bare soil, while the independent variables are composites built with multitemporal data and the ranked brightness approach (Hansen et al., 2003; Ramachandran et al., 2010). This dataset also has a spatial resolution of $500 \mathrm{~m} \times 500 \mathrm{~m}$. In this study, we only used data corresponding to VCF tree cover.

\subsection{Auxiliary data}

The US National Aeronautics and Space Administration (NASA) conducted the Shuttle Radar Topography Mission (SRTM) to collect elevation data worldwide, which are included in the Geoportal of the Consultative Group on International Agricultural ResearchConsortium for Spatial Information (CGIAR-CSI). This information is available at $90-\mathrm{m}$ spatial resolution, with a vertical error of $16 \mathrm{~m}$ and a high pixel sensibility (1 m) (Getirana, 2010). Altimetry data from the SRTM mission were downloaded (http://srtm.csi. cgiar.org/) for the study area and re-projected to the same coordinate system. Before extracting topographic variables from the digital elevation model (DEM), resampling (bilinear interpolation) was applied to the

Table 2 Spectral bands of MCD43A4 MODIS product

\begin{tabular}{|c|c|c|c|c|c|}
\hline Band $\left(\rho_{\lambda}\right)$ & Name & $\begin{array}{l}\text { Wavelengh range } \\
(\mathrm{nm})\end{array}$ & Unit & Radiometric resolution & Spatial resolution $(\mathrm{m})$ \\
\hline$\rho_{1}$ & Red & $620-670$ & Reflectance, dimensionless & 16 bit & 500 \\
\hline$\rho_{2}$ & Near infrared & $841-876$ & Reflectance, dimensionless & 16 bit & 500 \\
\hline$\rho_{3}$ & Blue & $459-479$ & Reflectance, dimensionless & 16 bit & 500 \\
\hline$\rho_{4}$ & Green & $545-565$ & Reflectance, dimensionless & 16 bit & 500 \\
\hline$\rho_{5}$ & Middle infrared 1 & $1,230-1,250$ & Reflectance, dimensionless & 16 bit & 500 \\
\hline$\rho_{6}$ & Middle infrared 2 & $1,628-1,652$ & Reflectance, dimensionless & 16 bit & 500 \\
\hline$\rho_{7}$ & Middle infrared 3 & $2,105-2,155$ & Reflectance, dimensionless & 16 bit & 500 \\
\hline
\end{tabular}


elevation dataset to spatially match it with the satellite dataset at $500 \mathrm{~m} \times 500 \mathrm{~m}$ spatial resolution, the main data source. Several topographic variables were obtained from the resampled DEM as follows: elevation, slope, slope orientation (azimuth 0 to $360^{\circ}$ ) and standard deviation of slope orientation. Another auxiliary variable used was the horizontal distance to the nearest stream (Blackard et al., 2008) obtained by processing vector maps at 1:250,000 scale from the National Institute of Statistics and Geography of Mexico (INEGI, its acronym in Spanish).

As climatic predictor variables, both MAP and minimum temperature of the coldest month (TCM) were used. These variables have ecological meaning as they limit biomass production in ecosystems; wetter and warmer conditions are likely to support taller trees and vice versa. Data from 308 weather stations located within the study area were obtained from the Extractor of Climatic Data database (ERIC, its acronym in Spanish) (IMTA, 2006). To spatially extend the climatic data from weather stations, point data were interpolated by the ordinary kriging method using a spherical model. The mean square error obtained for MAP was $182.7 \mathrm{~mm}(r=0.91, P<0.01$; predictions vs observations). The same parameter for TCM was $1.61^{\circ}(r=0.79, P<0.01)$. All auxiliary datasets including topographic and climatic predictor variables were homogenized at $500 \mathrm{~m} \times 500 \mathrm{~m}$ spatial resolution.

\subsection{Multicollinearity diagnosis}

Two of the variables $\left(\mathrm{NDVI}_{62}\right.$ and VCF) used were obtained from satellite imagery. Therefore, we expected to have multicollinearity problems. High cor- relation (multicollinearity) between explaining variables is a situation often investigated when applying parametric regression. A way to diagnose multicollinearity is through the analysis of the variance inflation factor (VIF). VIF indicates how much multicollinearity degrades the precision of the model. Thus, $\mathrm{VIF}_{\mathrm{j}}=1 /\left(1-\mathrm{R}_{\mathrm{j}}{ }^{2}\right)$, where $\mathrm{R}_{\mathrm{j}}{ }^{2}$ is the multiple correlation coefficient between the variable $\mathrm{j}$ and the other independent variables. VIF values greater than 10 indicate the presence of multicollinearity (Fox, 1984; Sarker and Nichol, 2011; Joseph, 2012). After a VIF analysis of our dataset, we found no multicollinearity problems. The VIF estimated values are in Table 3.

\subsection{The algorithm $k$-nearest neighbor $(k N N)$}

The $k \mathrm{NN}$ algorithm was used to estimate aboveground biomass. In brief, this algorithm interpolates field attributes considering the $k$-nearest neighbors based on the $\mathrm{n}$-dimensional space. First, multivariate distances from the target pixel to all sampled pixels in the sample dataset are computed. Then these distances are sorted and those with the smallest distances are used to determine the $k$-nearest neighbors to the target pixel. Finally, an average value that is inversely weighted taking into account the multivariate distances between the optimum number of identified $k$-nearest neighbors is estimated. This method does not require statistical assumptions about the nature of the data, e.g. normality or homoscedasticity (Gjertsen, 2007; Baffeta et al., 2009; Breidenbach et al., 2012).

Several variations of the $k \mathrm{NN}$ algorithm have been implemented to improve its performance (Packalén and Maltamo, 2007; Hudak et al., 2008; Nothdurf and

Table 3 Estimated values of variance inflation factors (VIF) of predictor variables and their acronyms

\begin{tabular}{llcc}
\hline \multicolumn{1}{c}{ Group } & \multicolumn{1}{c}{ Variable } & Acronym & VIF \\
\hline \multirow{2}{*}{ Satellite variables } & Normalized Difference Vegetation Index built with $\rho_{6}$ and $\rho_{2}$ & NDVI $_{62}$ & 2.771 \\
& Vegetation continuous fields & VCF & 2.990 \\
Climatic variables & Mean annual precipitation & MAP & 3.078 \\
& Temperature of coldest month & TCM & 3.735 \\
& Elevation & Not used & 4.872 \\
& Slope & Not used & 1.250 \\
Topographic variables & Slope orientation & Not used & 1.064 \\
& Standard deviation of slope orientation & Not used & 1.125 \\
& Distance to nearest stream & Not used & 1.123 \\
\hline
\end{tabular}


Saborowski, 2009; Breidenbach et al., 2010). They focus on alternative approaches to calculate the distances used to estimate a new value from sampling points. Here, we tested four variations of the method (Table 4). When the unstandardized multivariate distance (RAW) method is used, predictor variables are not properly weighted because multivariate distances are unstandardized. This causes explanatory variables with higher variance to dominate the estimation procedure. In the Euclidean (EUC) method, a normalization by subtracting the mean and dividing by the standard deviation for each predictor variable is used to standardize multivariate distances. When using the Mahalanobis distance (MAH), the predictor variables are already standardized because the method takes into account the correlation structure between predictor variables using the inverse of the covariance matrix of the X's. While when using the MSN method, the distance metrics is generated from canonical correlation analysis. The weights, in addition to the variables, are already standardized, which maximizes the linear correlation between the response variable and explanatory variables (Loog et al., 2005; Table 4).

Table 4 Distance metrics used

\begin{tabular}{ll}
\hline \multicolumn{1}{c}{ Method } & Description \\
\hline Raw (RAW) & It is the Euclidean distance without normalization. \\
Euclidean (EUC) & $\begin{array}{l}\text { It is computed in a multivariate predictor variable space normalized by subtracting the mean and dividing } \\
\text { by the standard deviation for each predictor variable. }\end{array}$ \\
Mahalanobis (MAH) & It is the Euclidean distance weighted by the inverse of the predictor-variables covariance matrix. \\
& $\begin{array}{l}\text { It is the Euclidean distance weighted by } W=\Gamma \Lambda^{2} \Gamma^{T} \text {, where } \Gamma \text { is the matrix of canonical vectors cor- } \\
\text { responding to the predictor variables (X's) found by canonical correlation analysis between X and Y, and } \\
\end{array}$ \\
\hline
\end{tabular}

Note: description is cited from Crookston and Finley (2008) and Hudak et al. (2008).

\subsection{Variable selection}

The selection of an appropriate set of explanatory variables is not a trivial matter. To accomplish such a task, we decided to heuristically evaluate the performance of each group of predictor variables (satellite, climatic, and topographic) using the cross-validation leave-one-out technique, for a sequence from $k=1-30$ (Chirici et al., 2008; McRoberts, 2008). A modified interpretation of the root mean square error (RMSE) was used as a measure of the contribution of each explanatory variable to the estimation of the variable of interest (biomass). Crookston and Finley (2008) suggested changing the error term to root mean square deviation (RMSD), difference instead of error, since the model error does not come from minimizing the square root of the differences between two datasets. To calculate absolute RMSD the following equation was used:

$$
R M S D=\sqrt{\frac{\sum_{i=1}^{n}\left(y_{i}-\hat{y}_{i}\right)^{2}}{n}} .
$$

Where, $y_{i}$ and $\hat{y}_{i}$ are observed and estimated biomass values $\left(\mathrm{Mg} / \mathrm{hm}^{2}\right)$, respectively; $n$ is the number of targets.

Relative RMSD (\%) was calculated by dividing RMSD by the mean predicted biomass for the targets and then multiplying it by 100 in order to obtain a percentage value.

To achieve confidence on the predictor variable selection method used, we also performed the commonly used stepwise regression analysis to identify relevant explanatory variables. Some authors have used this procedure to select predictor variables for the $k \mathrm{NN}$ algorithm using a significance level $\alpha=0.15$ (Fuchs et al., 2009); for the case of this work, we used a threshold significance value of $\alpha=0.05$ to admit, and $\alpha=0.01$ to remove predictor variables (Gjertsen, 2007).

\subsection{Method selection}

Once the best predictor variables were selected, we tested four variations of the distance metric as described in Table 4. This test was accomplished in three phases: 1) running again the cross validation (leave- 
one-out) technique to compare RMSD values for each method and also to determine an optimal $k$ value; 2) carrying out a pairwise means comparison of RMSD values using the Duncan test $(\alpha=0.05)$ to group approaches with similar performances; and 3) comparing performances of all methods by graphing observed versus predicted biomass values and calculating a Pearson correlation coefficient.

\subsection{Aboveground biomass estimation}

Finally, an aboveground biomass map for the forested area was generated by applying the selected distance metrics into the $k \mathrm{NN}$ algorithm. For comparison purposes, we also used the latest official Mexican land use and vegetation map series IV (INEGI, 2009) to estimate a mean total value of aboveground biomass for each vegetation type presented in the map. This task was achieved by averaging, on a per pixel basis, the estimated biomass values within a given vegeta-
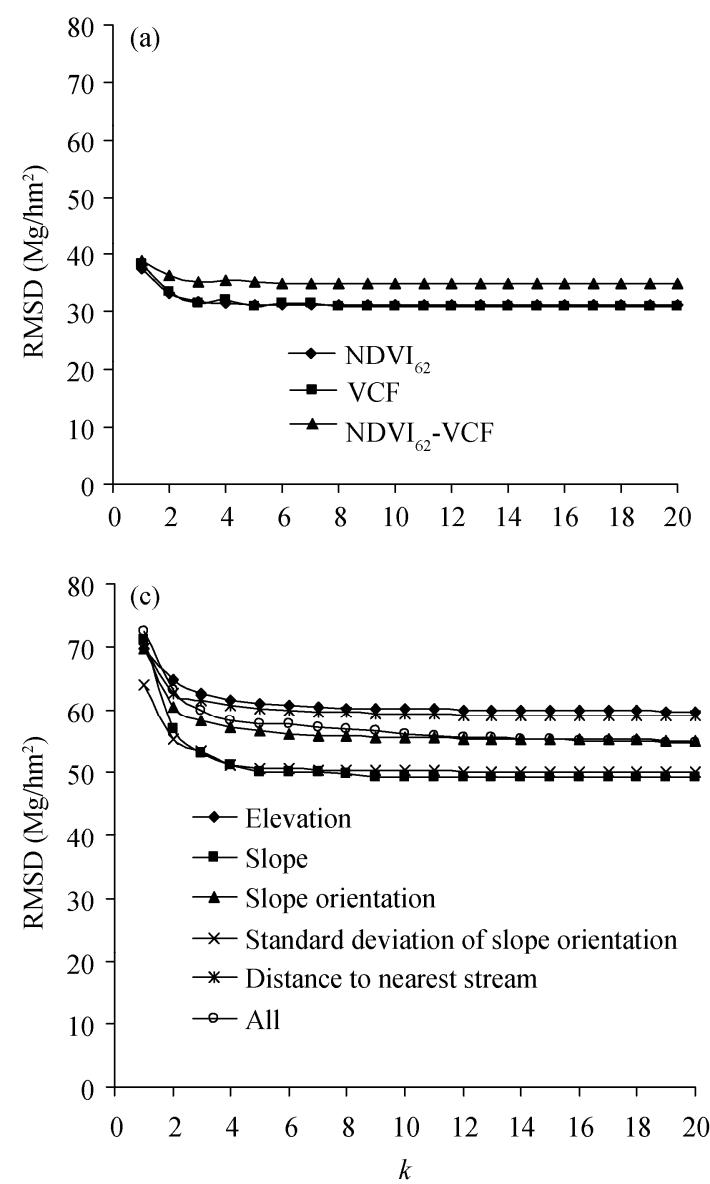

tion type. Standard error of the mean was estimated according to McRoberts (2008). The vegetation map was also used to mask out non-forested areas. The date of remotely-sensed imagery used by INEGI to make the official map is close to both the date of the field campaign of forest inventory data (2004-2006) and the date of spectral data (2006) used in this study. Data processing was performed in $\mathrm{R}$ statistical computing software using the library yaImpute (Crookston and Finley, 2008).

\section{Results}

\subsection{Variable selection}

The explanatory variables that showed the smallest RMSD values for estimating aboveground biomass were $\mathrm{NDVI}_{62}$ and VCF (from 30 to $36 \mathrm{Mg} / \mathrm{hm}^{2}$ ) (Fig. 3a). Then, climatic variables followed (Fig. 3b): in
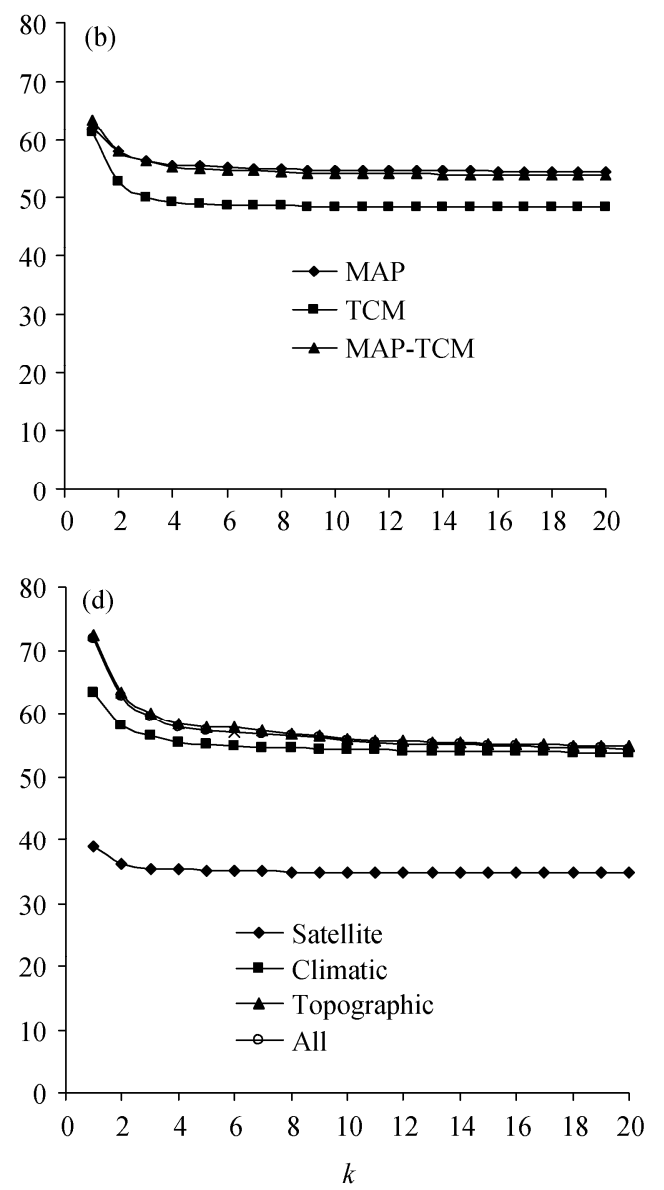

Fig. 3 RMSD values for different $k$-nearest neighbors calculated using the cross-validation leave-one-out technique and the unstandardized multivariate distance (RAW) implementation of the kNN algorithm; (a) satellite variables, (b) climatic variables, (c) topographic variables, and (d) all groups of variables 
this case, TCM presented the lowest RMSD of their group $\left(\approx 48 \mathrm{Mg} / \mathrm{hm}^{2}\right)$. The topographic variables were the poorest predictors (Fig. 3c): slope and variability of orientation showed RMSDs of 49 and $51 \mathrm{Mg} / \mathrm{hm}^{2}$, respectively. We also compared the performance of predictor variables among groups. The decreasing RMSD was evident for the case of satellite-derived variables ( $\mathrm{NDVI}_{62}$ and $\mathrm{VCF}$ ) (Fig. 3d).

Variable selection, made by comparing the RMSD, was successfully validated by applying the stepwise regression based on the significance levels previously indicated ( $\alpha=0.05$ and $\alpha=0.01$ for admitting and removing variables, respectively). Hence, the only explanatory variables that met these significance levels were $\mathrm{NDVI}_{62}$ and VCF $(P<0.0001)$, while the remaining variables (e.g. climatic and topographic) were not statistically significant.

\subsection{Method selection}

Once $\mathrm{NDVI}_{62}$ and VCF were selected as predictor variables, the four distance metrics presented above were evaluated using a cross-validation procedure. Both Figs. 4a and $\mathrm{b}$ describe the behavior of the RMSD values as $k$ increases. An additional decrease in the RMSD is clear when using any of the selected standardized distances (EUC, MAH or MSN). The maximum performance was by the EUC method (lowest $\mathrm{RMSD}=29.57 \mathrm{Mg} / \mathrm{hm}^{2}$, optimal $k=10$ ). Secondly, we had the MAH method (RMSD=29.91 $\mathrm{Mg} / \mathrm{hm}^{2}$, optimal $k=6$ ); thirdly, the MSN method (RMSD $=30.56 \mathrm{Mg} / \mathrm{hm}^{2}$, optimal $k=14$ ); and finally, the unstandardized spectral distance (RAW) (RMSD= $31.69 \mathrm{Mg} / \mathrm{hm}^{2}$, optimal $k=11$ ). In order to determine whether there were significant differences of the RMSD values between methods obtained in the crossvalidation phase, we carried out a pairwise means comparison using the Duncan test $(\alpha=0.05)$ (GarcíaVillalpando et al., 2001). This test showed no significant differences between the methods using standardized distance metrics (EUC, MAH and MSN), but significant differences were detected against the RAW distance metric. According to Duncan's test, the methods can be classified into two groups: Group 1, which includes any of the standardized distances; and
Group 2, which includes the RAW distance method. In other words, by means of RMSD, standardized distance methods worked statistically similarly.

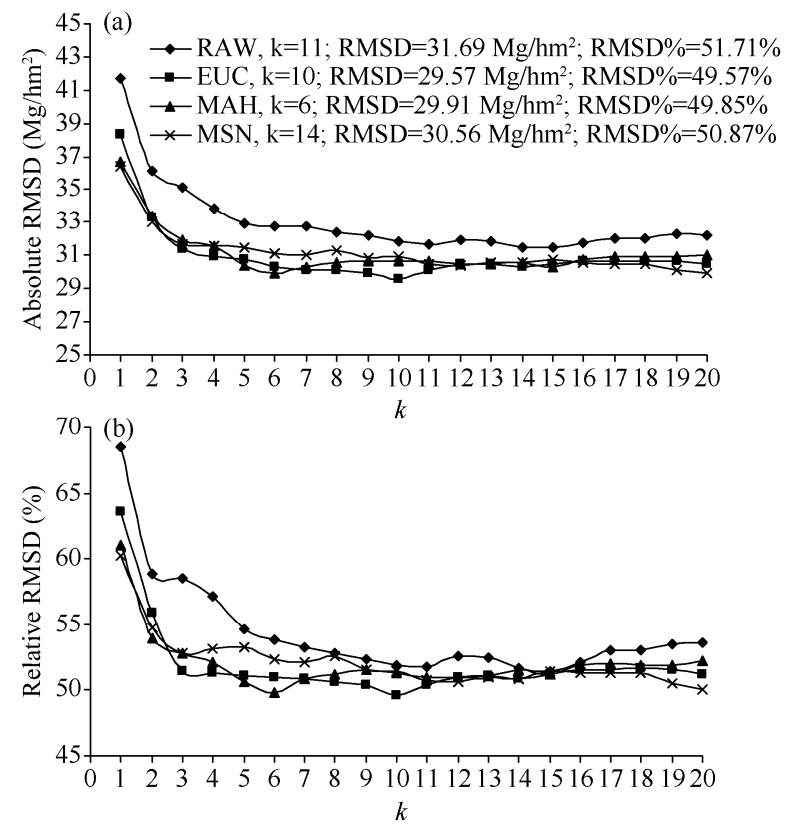

Fig. 4 RMSD values for different $k$-nearest neighbors calculated using different distance metrics and the $\mathrm{NDVI}_{62}$ and VCF variables

To gain confidence in selecting the best interpolation $k \mathrm{NN}$ method, we computed correlations contrasting the observed versus estimated values. All correlations obtained by the four methods were highly significant and are as follows: MSN $(r=0.90)$, MAH $(r=0.88)$, EUC $(r=0.86)$ and RAW $(r=0.84)$. Such correlations seemed to be very similar, thus we used the Steiger's method in order to investigate the significant differences between such correlations (Steiger, 1980). In Table 5, the probability values indicate which correlations statistically differ from the others. Undoubtedly, the correlation estimated for the MSN distance metric $(r=0.90)$ significantly differed $(P=0.0001)$ from that obtained for the RAW one $(r=0.84)$. Secondly, the MSN correlation $(r=0.90)$ was successfully differentiated $(P=0.0015)$ from that obtained by the EUC method $(r=0.86)$. But, the correlation comparison for the MSN $(r=0.90)$ and MAH $(r=0.88)$ methods did not successfully differentiated them. Based on this analysis, we can state that MSN and MAH methods showed similar correlation coefficients. 
When analyzing Fig. 5 with observed and estimated values, an underestimation in both RAW and MAH distance metrics can be detected, whereas the other two approaches showed a better fit, peaking for the MSN. Although MSN and MAH distance metrics showed the highest correlations, we decided to select the MSN to estimate the multivariate distance metrics into the $k \mathrm{NN}$ algorithm for mapping aboveground biomass using NDVI and VCF as predictor variables in San Luis Potosi, Mexico.

\subsection{Aboveground biomass by vegetation type}

Shrubland is the prevailing plant formation in the study area. It covers more than $75 \%\left(3,009,300 \mathrm{hm}^{2}\right)$ of the territory and includes plant species whose morphology and physiology are adapted to arid and semiarid climates with long periods of water scarcity ( $<600 \mathrm{~mm}$ of annual precipitation). Plant genera found in shrubland are as follows: Larrea spp., Agave spp., Opuntia spp., Stenocereus spp. and Prosopis spp. Aboveground biomass stocks estimated for these

Table 5 Results of significance test of difference between correlations

\begin{tabular}{ccccccc}
\hline Method & RAW & EUC & MAH & MSN & $r$ & LB \\
\hline RAW & - & & & 0.84 & 0.7977 \\
EUC & $P=0.0825$ & - & & 0.8740 \\
MAH & $P=0.0019^{*}$ & $P=0.066$ & - & 0.8225 & 0.8900 \\
MSN & $P=0.0001^{*}$ & $P=0.0015^{*}$ & $P=0.0697$ & - & 0.88 & 0.8474 \\
\hline
\end{tabular}

Note: LB and UB are lower and upper bound, respectively, at $95 \%$ confidence interval. ${ }^{*}$ indicates that the correlation is statistically different ( $\alpha=0.05$ ).
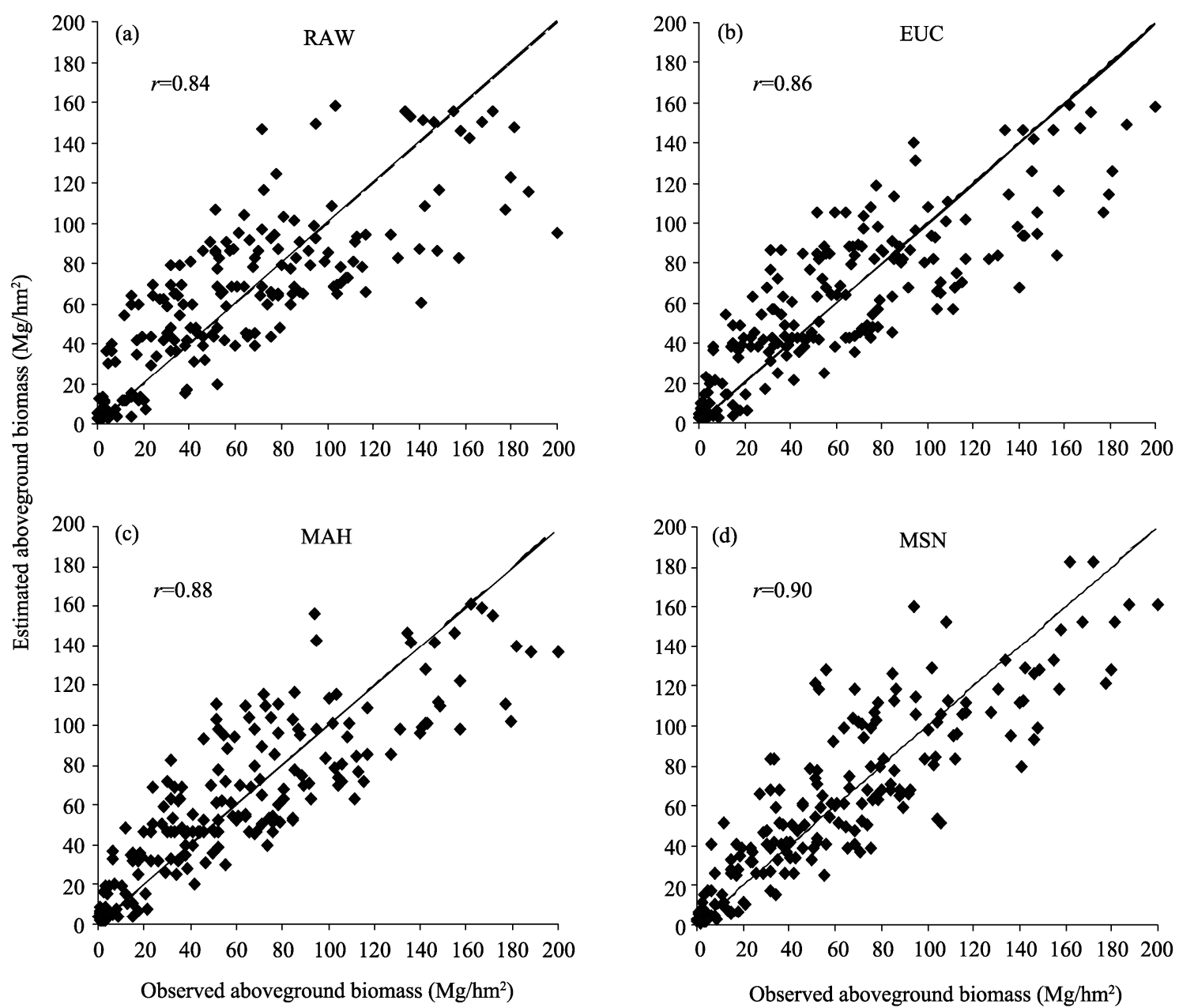

Fig. 5 Effect of using different distance metrics on the $k \mathrm{NN}$ algorithm performance via correlation of observed and estimated values of aboveground biomass in San Luis Potosi, Mexico 
ecosystems were an average of $7.5 \mathrm{Mg} / \mathrm{hm}^{2}$. Lasserre et al. (2011) estimated the biomass content of a bush in Italy using satellite images and $k \mathrm{NN}$ nonparametric estimator ranging from 0.5 to $4 \mathrm{Mg} / \mathrm{hm}^{2}$. Other authors have studied the vegetation type of shrubland and encountered different values of aboveground biomass. For example, Robles et al. (2008) found values between 1.2 and $4.0 \mathrm{Mg} / \mathrm{hm}^{2}$ for Dasylirion spp. aboveground biomass. Navarro-Cerrillo and BlancoOyonarte (2006) estimated values of carbon stocks in aboveground biomass of various dominant shrubland species such as Citus ladanifer L. with $2.2 \mathrm{Mg} / \mathrm{hm}^{2}$ (4.4 Mg/hm ${ }^{2}$ for aboveground biomass) and Pistacia lentiscus L. with $9.8 \mathrm{Mg} / \mathrm{hm}^{2}\left(19.6 \mathrm{Mg} / \mathrm{hm}^{2}\right.$ for aboveground biomass). Our estimates of aboveground biomass for shrubland ranged from 1.2 to $25 \mathrm{Mg} / \mathrm{hm}^{2}$, averaging $7.5 \mathrm{Mg} / \mathrm{hm}^{2}$.

MSN was selected to spatially estimate aboveground biomass for the study area (Fig. 6). The values of aboveground biomass estimates by vegetation cover type are in the following order: coniferous forest, oak forest, cloud forest, shrubland, tropical dry forest, tropical humid forest. The coniferous forest (Juniperus spp. and Pinus spp.) found in the study area corresponded to semiarid land and showed a low content of aboveground biomass $\left(42 \mathrm{Mg} / \mathrm{hm}^{2}\right)$. This type of forest includes species morphologically adapted to arid climates with low growth rates and thus small biomass/carbon stocks. Powell et al. (2010) reported values of biomass for temperate forests in Arizona and Minnesota ranging from $45 \mathrm{Mg} / \mathrm{hm}^{2}(150-880 \mathrm{~mm}$ of annual precipitation) to $60 \mathrm{Mg} / \mathrm{hm}^{2}$ (490-1090 mm of annual precipitation). The oak forest (Quercus spp.) has a higher average aboveground biomass stock (70.9 $\mathrm{Mg} / \mathrm{hm}^{2}$ ) and can be found in higher elevations of mountains with an increasing tendency towards the east because wet winds come from that direction (Gulf of Mexico) and cause an average annual rainfall of $>1,000 \mathrm{~mm}$. In the category of forests, cloud forests showed the highest average aboveground biomass stock $\left(121.1 \mathrm{Mg} / \mathrm{hm}^{2}\right)$. This vegetation type is present in $0.2 \%\left(7,975 \mathrm{hm}^{2}\right)$ of the study area and has a diversity of tall tree species mainly including the genera Quercus and Liquidambar spp. (Valdez-Tamez et al., 2003). Acosta Mireles et al. (2009) determined the carbon stock in mixed forests of Pinus patula in Tlaxcala, Mexico. For the aboveground compartment, these ecosystems present values between 118.3 $\mathrm{Mg} / \mathrm{hm}^{2}$ (236.6 Mg/hm² of aboveground biomass) and $77.2 \mathrm{Mg} / \mathrm{hm}^{2}\left(144.4 \mathrm{Mg} / \mathrm{hm}^{2}\right.$ of aboveground biomass).

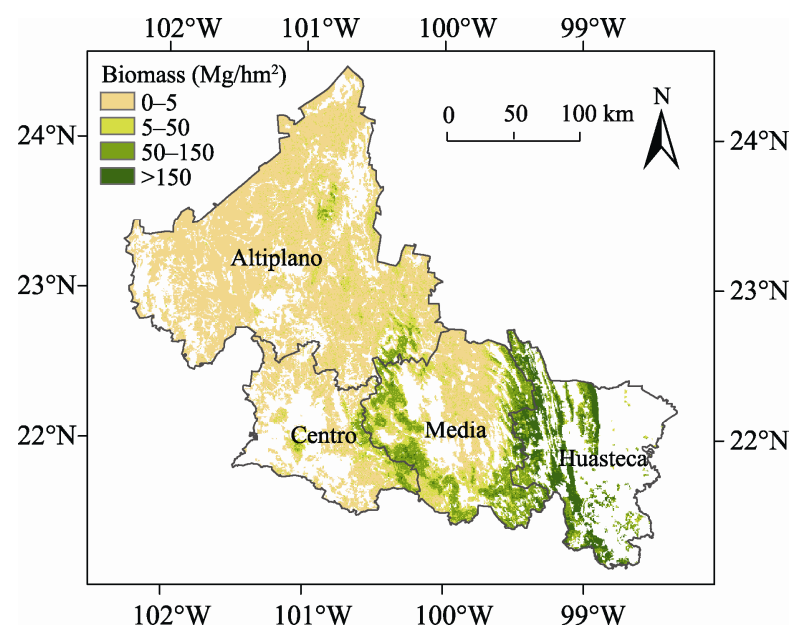

Fig. 6 Aboveground biomass map for San Luis Potosi, Mexico, obtained with $k N N$ algorithm using $\mathrm{MSN}$ spectral distance (RMSD=30.56 Mg/hm², $k=14, r=0.90$ )

A minimal part of the study area is covered by tropical forest $(4.5 \%)$ (Table 6$)$. This ecosystem presented the highest aboveground biomass with an average of $152.7 \mathrm{Mg} / \mathrm{hm}^{2}$, ranging from $1.9-219.2$ $\mathrm{Mg} / \mathrm{hm}^{2}$. The large variation of estimated values of aboveground biomass at pixel level is due to high ecosystem fragmentation. Although this paper presents a case study of a spatially-explicit estimation of aboveground biomass in San Luis Potosí, Mexico, mean biomass values estimated by vegetation type (Table 6) can be generalized to other regions with similar climatic characteristics. Normally, tropical forests are under heavy human pressure which leads to high rates of habitat loss. Reyes-Hernández et al. (2006) found that the tropical rain forest of the study area was almost completely lost during the period of 1973-2000 (the area was reduced from 98,272 to $10,226 \mathrm{hm}^{2}$ ). Miranda-Aragón et al. (2012) stated that more than $70 \%$ of the remaining tropical ecosystems of the same study area present high probability of deforestation due to agriculture and livestock activities. This intra-polygon of vegetation variation was detected because remotely-sensed data adequately cap- 
tured human-induced ecosystem variability. To better understand the spatial patterns of landscapes in terms of aboveground biomass and to determine a quantitative measure of the level of fragmentation of these remaining ecosystems, further research needs to focus on studying the spatial patterns of gaps in arid, temperate, and tropical ecosystems on more detailed spatial scales.

\section{Discussion}

This paper examines some spectral satellite data-based, topographic and climatic predictor variables and four variations of distance metrics applied to the $k$-nearest neighbor algorithm for estimating aboveground biomass. Most related research has focused on studying the ability of spectral vegetation indices to estimate forest density variables, the red-infrared domain spectral indices being the ones that have captured the attention of researchers. Current literature (2007 to date) documents the potential of spectral indices based on the shortwave or middle infrared for estimating forest density variables (Gjertsen, 2007; Fuchs et al., 2009). For example, Gjertsen (2007) estimated wood volume using Landsat TM spectral data as predictors and found that the spectral variables that best explain forest density are $\mathrm{TM}_{4}$ (near Infrared) and $\mathrm{TM}_{7}$ (short- wave infrared). These results support our work. The spectral bands they used are comparable to the MODIS MCD43A4 product used here to build the vegetation spectral index $\mathrm{NDVI}_{62}$. In another study, Aguirre-Salado et al. (2009) used the $\mathrm{NDVI}_{43}$, a water stress index built with spectral data from the SPOT5 HRG sensor (10-m spatial resolution), and found it appropriate to describe the forest density in coniferous forests at a high spatial resolution. The spectral index $\mathrm{NDVI}_{43}$ is equivalent to the $\mathrm{NDVI}_{62}$ presented in this research as it involves equivalent spectral bands and is therefore comparable. Fuchs et al. (2009) used data from the ASTER sensor (15-m spatial resolution) to estimate tree carbon stocks in the Siberian tundra and found that the best predictor variables included spectral bands in the shortwave infrared portion with correlation values ranging from 0.52 to 0.57 . Canisius et al. (2010) also recognized that avoiding shortwave infrared bands in the analysis could lead to a decrease in desired correlations. Cruz-Leyva et al. (2010) modeled forest density variables such as basal area and wood volume in a forest of Pinus patula and P. teocote in Hidalgo, Mexico using both spectral variables from SPOT5 HRG and auxiliary information (climatic and topographic data). They concluded that the best models were developed using only spectral data.

Table 6 Estimates of mean aboveground biomass for each vegetation type obtained with $k N N$ algorithm (MSN distance) (RMSD=30.56 $\left.\mathrm{Mg} / \mathrm{hm}^{2}, k=14, r=0.90\right)$ in San Luis Potosi, Mexico

\begin{tabular}{lccccccc}
\hline Vegetation type & Climate & Area $\left(\mathrm{hm}^{2}\right)$ & Proportion $(\%)$ & $\begin{array}{c}\text { Mean above- } \\
\text { ground bio- } \\
\text { mass } \\
\left(\mathrm{Mg} / \mathrm{hm}^{2}\right)\end{array}$ & SE & $\begin{array}{c}\text { Total biomass } \\
(\mathrm{Mg})\end{array}$ & $\begin{array}{c}\text { Biomass } \\
\text { estimates by De } \\
\text { Jong et al. }(2010) \\
\left(\mathrm{Mg} / \mathrm{hm}^{2}\right)\end{array}$ \\
\hline Shrubland & Arid-semiarid & $3,009,300$ & 76.5 & 7.5 & 16.5 & $22,469,501.3$ & $\left(\mathrm{SL}^{*}\right) 12-40$ \\
Oak forest & Semiarid & 440,925 & 11.2 & 70.9 & 60.2 & $31,246,247.6$ & $\left(\mathrm{BF}^{*}\right) 62$ \\
Tropical dry forest & Semiarid & 185,825 & 4.7 & 122.9 & 64.2 & $22,844,075.3$ & $\left(\mathrm{TDF}^{*}\right) 38$ \\
Tropical humid forest & Humid & 175,725 & 4.5 & 152.7 & 61.3 & $26,831,917.6$ & $\left(\mathrm{THF}^{*}\right) 104$ \\
Coniferous forest & Semiarid & 116,250 & 3.0 & 42.0 & 45.2 & $4,880,300.5$ & $\left(\mathrm{CF}^{*}\right) 94$ \\
Cloud forest & Humid & 7,975 & 0.2 & 121.1 & 49.0 & $965,570.5$ & $\left(\mathrm{THF}^{*}\right) 104$ \\
Total for the study area & & $3,936,000$ & & & & $109,237,612.8$ & \\
\hline
\end{tabular}

Note: SE, standard error of the mean (McRoberts, 2008). \%, percentage of area occupied by vegetation type related to the total study area. *, vegetation classes used by De Jong et al. (2010), who reported values of carbon in aboveground biomass, so values presented here were multiplied by factor 2 for being scaled to biomass values. CF, coniferous forest; BF, broadleaved forest; THF, tropical humid forest; SL, arid and semiarid vegetation; TDF, tropical dry forest.

A motivation for the use of auxiliary variables in this study is the potential increase in the precision of the estimation. However, this and previous studies confirm that in the case of estimating forest density, an increase in correlation values when using auxiliary variables is not necessarily true. However, there are 
other cases of research which are focused differently, e.g. for the determination of potential habitats for plants and animals, particularly with logistic regression analysis, where the use of auxiliary information such as climatic or topographic variables is still relevant and valid (Chen et al., 2007; Hongoh et al., 2012).

In our analyses, topographic variables were obtained after resampling the digital elevation model from $90-\mathrm{m}$ to $500-\mathrm{m}$ pixel size. We decided to include auxiliary (climatic and topographic) data into our analysis in order to get some improvement on estimation precision. Blackard et al. (2009) estimated aboveground biomass in the United States of America by MODIS spectral, climatic, and topographic data using a regression tree algorithm. When all groups of variables were used together, they found an increase in variable importance. They measured variable importance as percent improvement or decrease in relative error. When each major group of explaining variables was used alone as a predictor set in different models of biomass, the variable importance they found matches our results. MODIS spectral and climatic data showed better performance than topographic data for estimating aboveground biomass. They resampled $30-\mathrm{m}$ digital elevation models to $250-\mathrm{m}$ pixel size to coincide with the MODIS spectral data. Improvement of precision on the estimates in Blackard et al. (2009) can be attributed to the increase of the number of explaining variables used. This effect can be similar to that caused when determining the coefficient of determination in statistical models by including a higher number of predictor variables. In our case $(k N N)$, using all explaining variables together did not produce any improvement in the estimates. Therefore, we decided to use only statistically-significant explaining variables determined in the stepwise regression phase to carry out spatially-explicit aboveground biomass estimation. Satellite image-based variables $\left(\mathrm{NDVI}_{62}\right.$ and $\mathrm{VCF}$ ) were the only significant ones because they are strongly correlated with biomass stock in the field.

When comparing different approaches or spectral data sources based on their performance, normally error (Bias or RMSE) or correlation (Pearson correlation coefficient) measurements are used. A common idea is that lesser spatial resolution studies could have higher errors (RMSE) or lower correlations. This is not necessarily true. Many studies carried out with moderate spatial resolution spectral data presented high correlations (Anaya et al., 2009; Blackard et al., 2009; Canisius et al., 2010). Moderate spatial resolution sensors are often used to cover large study areas $\left(>1 \times 10^{6} \mathrm{hm}^{2}\right)$ with high quality spectral records and to have spatially consistent aboveground biomass estimates at the regional level. However, low detail achieved by moderate spatial resolution sensors is not useful to prescribe land management activities at the local level.

Discussion about the optimal number of nearest neighbors $(k)$ and errors obtained with significant predictor variables is as follows. According to this work, the optimal $k$ for each method was 6,10,11 and 14 for MAH, EUC, RAW and MSN, respectively. The optimal values found are within the range reported in the literature: (5 $\geq k \leq 20)$ (Gjertsen, 2007; Chirici et al., 2008; Kajisa et al., 2008; Aguirre-Salado et al., 2009; Baffeta et al., 2009; Fuchs et al., 2009; McRoberts, 2009; Breidenbach et al., 2012).

The RMSD values obtained at pixel level in this investigation ranged from $29-32 \mathrm{Mg} / \mathrm{hm}^{2}(49 \%-52 \%$ of the means) and are also consistent with other values found in recent works that study forest biomass. For example, Blackard et al. (2008) used tree regression techniques and various types of MODIS products as well as climatic, topographic, and forest inventory data to map forest biomass in the USA. They obtained a relative error at pixel level that varies from $51 \%$ in the territory of Puerto Rico to $92 \%$ in the southern United States. In another study, Labrecque et al. (2006) generated spatially-explicit forest biomass estimates for Canada through the $k \mathrm{NN}$ algorithm (RAW method) using Landsat TM data and inventory data. The RMSE (equivalent to RMSD term) they obtained using $k=5$ nearest neighbors was $54 \mathrm{Mg} / \mathrm{hm}^{2}$. Reese et al. (2002) also applied the $k \mathrm{NN}$ algorithm (RAW method) to estimate forest biomass at pixel level in Sweden using Landsat 5 TM spectral data (30-m spatial resolution) and obtained a RMSE ranging from 53\% to $79 \%$ using $k=5$ nearest neighbors. Other authors who analyzed smaller but spatially more detailed areas found lower 
values of RMSE. For instance, Tian et al. (2012) mapped forest biomass for an area of $6,000 \mathrm{hm}^{2}$ through the $k \mathrm{NN}$ method by using Mahalanobis distance and SPOT 5 HRG spectral data (10-m spatial resolution, resampled to $20 \mathrm{~m}$ ). Their best set of predictor variables included the first two principal components, infrared index and elevation (as auxiliary information). They estimated aboveground biomass values ranging from 18 to $175 \mathrm{Mg} / \mathrm{hm}^{2}$ with a RMSE value of $20.7 \mathrm{Mg} / \mathrm{hm}^{2}$. These authors further decreased the estimated RMSE by incorporating mean tree height and forest canopy closure data derived from a LIDAR sensor, reaching a RMSE value of $15.2 \mathrm{Mg} / \mathrm{hm}^{2}$. These impressive levels of error are obtainable only with very high spatial resolution sensors, which usually means they can only be implemented in small areas. For large areas $\left(>1 \times 10^{6} \mathrm{hm}^{2}\right)$, this approach is still very challenging mainly due to the unavailability of spectrally-consistent and high spatial resolution data.

In Fig. 5d, the maximized linear correlation between predictor and response variables made by MSN distance metrics is reflected in a narrower prediction band. This explains why it is more suitable to work with standardized and uncorrelated variables, especially when spectral distances are calculated. Because the MSN method removes these two drawbacks in predictor variables, it becomes a good choice to implement the nearest neighbor estimation. Table 6 shows several average aboveground biomass values calculated by vegetation cover type. It also presents the biomass estimates by De Jong et al. (2010), who determined an average content of biomass for each vegetation type in Mexico using NFI data and vector maps made from manual photo-interpretation of remotely-sensed data by INEGI. Although their results are comparable to ours, they presented some underestimations, possibly due to the different methodology applied by both studies. De Jong et al. (2010) used allometric models grouped by levels of precipitation and argued that the most conservative estimates are better than overestimates of biomass. Our aboveground biomass estimates were made at genus and species levels using 25 models from the work by Návar (2009). This could be one important cause of such discrepancies in biomass estimation.

\section{Conclusion}

Multiple conclusions may be drawn from this study. First, the normalized difference vegetation index was built with near and shortwave infrared bands, and the vegetation continuous field variables had the best predictive performance to estimate aboveground biomass with the $k \mathrm{NN}$ algorithm. Second, after applying a Duncan test on the means of RMSD values obtained via cross-validation, we found that the examined methods can be grouped into unstandardized distance (RAW) and standardized distance (EUC, MAH and MSN). The performance shown by the three variations of the distance metrics confirms the gain achieved when standardizing spectral distances. Third, when MSN distance metric into $k \mathrm{NN}$ was used, the highest correlation between observed and estimated aboveground biomass $(r=0.9)$ was obtained. This confirms the effect of canonical correlation analysis on maximizing the correlation between explanatory variables and the response variable. Fourth, average estimates of aboveground forest biomass in shrubland, forest, and tropical rainforest of San Luis Potosi, Mexico, are between 5 and $150 \mathrm{Mg} / \mathrm{hm}^{2}$. Fifth, after removing non-forest areas via Boolean extraction, the sum of aboveground biomass of all pixels was $109.2 \times 10^{6} \mathrm{Mg}$. The $k \mathrm{NN}$ (MSN approach) spatially-explicit estimates represent a reliable picture of the current situation of aboveground biomass pools in San Luis Potosi, Mexico. This quantitative information on the forest resource can be used as a basis for designing an MRV system at the state level under the REDD+ initiative. Thus, higher spatial resolution and multi-temporal studies are needed to further monitor aboveground biomass dynamics at the local level.

\section{Acknowledgements}

The authors wish to thank the National Forestry Commission of Mexico for providing national forest inventory data. Special acknowledgement is given to two anonymous reviewers whose criticism and suggestions helped to deeply improve this paper.

\section{References}

Aguirre-Salado C A, Valdez-Lazalde J R, Ángeles-Pérez G, et al. 2009. 
Mapping aboveground tree carbon in managed Patula Pine forests in Hidalgo, Mexico. Agrociencia, 43: 209-220.

Anaya J A, Chuvieco E, Palacios-Orueta A. 2009. Aboveground biomass assessment in Colombia: a remote sensing approach. Forest Ecology and Management, 257: 1237-1246.

Baffeta F, Fattorini L, Franceschi S, et al. 2009. Design-based approach to $k$-nearest neighbours technique for coupling field and remotely sensed data in forest surveys. Remote Sensing of Environment, 113: $463-475$.

Barati S, Rayegan B, Saati M, et al. 2011. Comparison the accuracies of different spectral indices for estimation of vegetation cover fraction in sparse vegetated areas. The Egyptian Journal of Remote Sensing and Space Sciences, 14: 49-56.

Bhaduri K, Das K, Votava P. 2010. Distributed anomaly detection using satellite data from multiple modalities. In: Srivastava A, Chawla N, Yu P, et al. Proceedings of the 2010 Conference on Intelligent Data Understanding CIDU 2010, California: NASA Ames Research Center, 109-123.

Blackard J A, Finco M V, Helmer E H, et al. 2008. Mapping U.S. forest biomass using nationwide forest inventory data and moderate resolution information. Remote Sensing of Environment, 112: 1658-1677.

Breidenbach J, Naesset E, Lien V, et al. 2010. Prediction of species specific forest inventory attributes using a nonparametric semi-individual tree crown approach based on fused airborne laser scanning and multispectral data. Remote Sensing of Environment, 114: 911-924.

Breidenbach J, Naesset E, Gobakken T. 2012. Improving k-nearest neighbor predictions in forest inventories by combining high and low density airborne laser scanning data. Remote Sensing of Environment, 117: 358-365.

Cairns M, Olmsted I, Granados J, et al. 2003. Composition and aboveground tree biomass of a dry semi-evergreen forest on Mexico's Yucatan Peninsula. Forest Ecology and Management, 186: 125-132.

Canisius F, Fernandes R, Chen J. 2010. Comparison and evaluation of Medium Resolution Imaging Spectrometer leaf area index products across a range of land use. Remote Sensing Environment, 114: 950-960.

Chen H, Chen L, Albright T P. 2007. Predicting the potential distribution of invasive exotic species using GIS and information-theoretic approaches: a case of ragweed (Ambrosia artemisifolia L.) distribucion in China. Chinese Science Bulletin, 52(9): 1223-1230.

Chirici G, Barbati A, Corona P, et al. 2008. Non-parametric and parametric methods using satellite images for estimating growing stock volume in alpine and Mediterranean forest ecosystems. Remote Sensing Environment, 112: 2686-2700.

Colditz R, López-Saldaña G, Maeda P, et al. 2012. Generation and analysis of the 2005 land cover map for Mexico using $250 \mathrm{~m}$ MODIS data. Remote Sensing of Environment, 123: 541-552.
Cole T, Ewel J. 2006. Allometric equations for four valuable tropical tree species. Forest Ecology and Management, 229: 351-360.

Crookston N L, Finley A O. 2008. yaImpute: an R Package for kNN Imputation. Journal of Statistical Software, 23(10): 1-16.

Cruz-Leyva I A, Valdez-Lazalde J R, Ángeles-Pérez G, et al. 2010. Spatial modeling of basal area and tree volume in managed Pinus patula and P. teocote forests in the ejido Atopixco, Hidalgo. Maderay Bosques, 16(3): 75-97.

De Jong B, Anaya C, Masera O, et al. 2010. Greenhouse gas emissions between 1993 and 2002 from land-use change and forestry in Mexico. Forest Ecology and Management, 260(10): 1689-1701.

De Leeuw J, Georgiadou Y, Kerle N, et al. 2010. The function of remote sensing in support of environmental policy. Remote Sensing, 2: 1731-1750.

Etchevers-Barra J, Vargas-Hernández J, Acosta-Mireles M, et al. 2002. Aboveground biomass estimation by means of allometric relationships in six hardwood species in Oaxaca, Mexico. Agrociencia, 36: $725-736$.

FAO. 2009. State of The World's Forests. Food and Agriculture Organization of the United Nations. Rome: Electronic Publishing Policy and Support Branch Communication Division, 152 [2010-08-15]. http://www.fao.org/docrep/011/i0350e/i0350e00.htm.

Fox J. 1984. Linear Statistical Models and Related Methods: with Applications to Social Research. New York: John Wiley.

Franco-López H, Alan R E, Bauer M E. 2001. Estimation and mapping of forest stand density, volume, and cover type using the $k$-nearest neighbors method. Remote Sensing of Environment, 77: 251-274.

Fuchs H, Magdon P, Klein C, et al. 2009. Estimating aboveground carbon in a catchment of the Siberian forest tundra: combining satellite imagery and field inventory. Remote Sensing of Environment, 113: 518-531.

Gallaun H, Zanchi G, Nabuurs G J, et al. 2009. EU-wide maps of growing stock and above-ground biomass in forests based on remote sensing and field measurements. Forest Ecology and Management, 260(3): 252-261.

Galvao L, Dos Santos J, Roberts D, et al. 2011. On intra-annual EVI variability in the dry season of tropical forest: a case study with MODIS and hyperspectral data. Remote Sensing of Environment, 115: 2350-2359.

Gao B C. 1996. A normalized difference water index for remote sensing of vegetation liquid water from space. Remote Sensing of Environment, 58: 257-266.

García-Villalpando J, Castillo-Morales A, Ramírez-Guzmán M E, et al. 2001. A comparison of Tukey, Duncan, Dunnet, HSU and Bechhofer procedures for selection of means. Agrociencia, 35: 79-86.

Getirana A C V. 2010. Integrating spatial altimetry data into the automatic calibration of hydrological models. Journal of Hydrology, 387 : 244-255.

Gjertsen A K. 2007. Accuracy of forest mapping based on Landsat TM data and a kNN-based method. Remote Sensing of Environment, 110: 
$420-430$.

GOFC-GOLD. 2010. A sourcebook of methods and procedures for monitoring and reporting anthropogenic greenhouse gas emissions and removals caused by deforestation, gains and losses of carbon stocks in forests remaining forests, and forestation. Canada: GOFC-GOLD Project Office, Natural Resources, 203 [2010-02-10]. http://www.gofc-gold.uni-jena.de/redd/sourcebook.

Hansen M C, DeFries R S, Townshend J R, et al. 2003. MOD44B: vegetation continuous fields collection 3, version 3.0.0. Earth Interactions, 7: 1-20.

Hongoh V, Berrang-Ford L, Scott M E, et al. 2012. Expanding geographical distribution of the mosquito, Culex pipiens, in Canada under climate change. Applied Geography, 33: 53-62.

Hudak A T, Crookston N L, Evans J E, et al. 2008. Nearest neighbor imputation of species-level, plot-scale forest structure attributes from LiDAR data. Remote Sensing of Environment, 112: 2232-2245.

IMTA. 2006. Rapid Extractor for Climatic Information III, v. 1.0. Climatic information available in electronic format. Morelos, Mexico: Mexican Institute for Water Technology. [2010-02-15]. http://www. imta.gob.mx.

INEGI. 2009. Land Use and Land Cover Map Series IV. Mexico: National Institute of Geography and Statistics of Mexico. [2010-03-15]. http://www.inegi.org.mx.

Joseph M, Wang L, Wang F. 2012. Using Landsat imagery and census data for urban population density modeling in Port-au-Prince, Haiti. GIScience \& Remote Sensing, 49(2): 228-250.

Kajisa T, Murakami T, Mizoue N, et al. 2008. Estimation of stand volumes using the $k$-nearest neighbors method in Kyushu, Japan. Journal of Forest Research., 13: 249-254.

Kaul M, Dadhwal V K, Mohren G M J. 2009. Land use change and net C flux in Indian forests. Forest Ecology and Management, 258: 100-108.

Köhl M, Magnussen S S, Marchetti M. 2006. Sampling Methods, Remote Sensing and GIS Multiresource Forest Inventory. New York: Springer, 373.

Labrecque S, Fournier R, Luther J, et al. 2006. A comparison of four methods to map biomass from Landsat-TM and inventory data in western Newfoundland. Forest Ecology and Management, 226(1-3): 129-144.

Lasserre B, Chirici G, Chiavetta U, et al. 2011. Assessment of potential bioenergy from coppice forests through the integration of remote sensing and field surveys. Biomass and Bioenergy, 35(1): 716-724.

Loog M, Ginneken B, Duin R P. 2005. Dimensionality reduction of image features using the canonical contextual correlation projection. Pattern Recognition, 38(12): 2409-2418.

McRoberts R E. 2008. Using satellite imagery and the k-nearest neighbors technique as a bridge between strategic and management forest inventories. Remote Sensing Environment, 112: 2212-2221.

McRoberts R E. 2009. A two-step nearest neighbors algorithm using satellite imagery for predicting forest structure within species composition classes. Remote Sensing of Environment, 113: 532-545.

McRoberts R E. 2012. Estimating forest attribute parameters for small areas using nearest neighbors techniques. Forest Ecology and Management. 272: 3-12.

Miranda-Aragón L, Treviño-Garza E J, Jiménez-Pérez J, et al. 2012. Modeling susceptibility to deforestation of remaining ecosystems in North Central Mexico with logistic regression. Journal of Forestry Research, 23(3): 345-354.

Nakakaawa C A, Vedeld P O, Aune J B. 2011. Spatial and temporal land use and carbon stock changes in Uganda: implications for a future REDD strategy. Mitigation and Adaptation Strategies for Global Change, 16: 25-62.

NASA. 2009. MODIS Product Table. Sioux Falls, South Dakota: NASA Land Processes Distributed Active Archive Center (LP DAAC). https://lpdaac.usgs. gov/lpdaac/products/modis_products_table.

National Forestry Comission of Mexico. 2010. Manual of Procedures for Field Sampling. Jalisco, Mexico: National Forestry Comission of Mexico, 19 [2011-01-05]. http://www.cnf.gob.mx:8080/snif/portal/ compnent/phocadownload/category/153-2012?download=781:ma nual-del-remuestreo-infys-2012.

Návar J, Méndez E, Nájera A, et al. 2004. Biomass equations for shrub species of Tamaulipan thornscrub of northeastern Mexico. Journal of Arid Environments, 59: 657-674.

Návar J. 2009. Biomass component equations for Latin American species and groups of species. Annals of Forest Science, 66(2): 208.

Northup B, Sitzer S, Archer S, et al. 2005. Above-ground biomass and carbon and nitrogen content of woody species in a subtropical thornscrub parkland. Journal of Arid Environments, 62: 23-43.

Nothdurf A, Saborowski J. 2009. Spatial prediction of forest stand variables. European Journal of Forest Research, 128: 241-251.

Packalén P, Maltamo M. 2007. The k-MSN method for the prediction of species-specific stand attributes using airborne laser scanning and aerial photographs. Remote Sensing Environment, 109: 328-341.

Powell S L, Cohen W B, Healey S P, et al. 2010. Quantification of live aboveground forest biomass dynamics with Landsat time-series and field inventory data: a comparison of empirical modeling approaches. Remote Sensing of Environment, 114: 1053-1068.

Ramachandran B, Justice C, Abrams M. 2010. Land Remote Sensing and Global Environmental Change. NASA's Earth Observing System and the Science of ASTER and MODIS. New York: Springer, 894.

Reyes-Hernández H, Aguilar-Robledo M, Aguirre-Rivera J R, et al. 2006. Land cover and land use change in the Pujal-Coy project area, San Luis Potosí, Mexico, 1973-2000. Investigaciones Geográficas Boletín del Instituto de Geografía UNAM, 59: 26-42.

Robles A, España J, Robles H. 2008. Biomass and forage, spatial distribution and abundance of sotol (Dasylirion spp.) in the Ejido El Jazmin, Mazapil, Zacatecas, Mexico. Revista Investigación Científica, 4(2): 1-9. 
Rock B, Vogelmann J, Williams D, et al. 1986. Remote detection of forest damage. Bioscience, 36: 439-445.

Salis S, Assis M, Mattos P, et al. 2006. Estimating the aboveground biomass and wood volume of savanna woodlands in Brazil's Pantanal wetlands based on allometric correlations. Forest Ecology and Management, 228: 61-68.

Sampaio E, Silva G. 2005. Biomass equations for Brazilian semiarid caatinga plants. Acta Botânica Brasílica, 19: 935-945.

Sarker L, Nichol J. 2011. Improved forest biomass estimates using ALOS AVNIR-2 texture indices. Remote Sensing of Environment, 115: 968-977.

SAS Institute Inc. 2004. SAS/STAT 9.1 User's Guide. Cary, NC, USA: SAS Publishing, 5121.

Segura M, Kanninen M, Suarez D. 2006. Allometric models for estimating aboveground biomass of shade trees and coffee bushes grown together. Agroforestry Systems, 68: 143-150.

SEMARNAT-INE. 2009. Fourth National Communication of Mexico to the United Nations Framework Convention on Climate Change. Mexico: Ministry of Environment and Natural Resources-National Institute of Ecology, 274 [2010-04-15]. http://www2.ine.gob.mx/
publicaciones/consultaPublicacion.html?id_pub=654.

Silva-Arredondo F M, Návar-Chaidez J J. 2009. Estimating carbon expansion factors in temperate forest communities of northern Durango, Mexico. Revista Chapingo Serie Ciencias Forestales y del Ambiente, 15(2): 155-163.

Streck C, O'Sullivan R, Janson-Smith T. 2008. Climate Change and Forests: Emerging Policy and Market Opportunities. Baltimore: Brookings Institution Press, 346.

Tian X, Su Z, Chen E, et al. 2012. Estimation of forest above-ground biomass using multi-parameter remote sensing data over a cold and arid area. International Journal of Applied Earth Observation, 14: $160-168$.

Tomppo E, Olsson H, Stahl G, et al. 2008. Combining national forest inventory field plots and remote sensing data for forest databases. Remote Sensing of Environment, 112: 1982-1999.

Valdez-Tamez V, Rahim-Foroughbakhch P, Gláfiro-Alanís F. 2011. Relict distribution of cloud forest in Northeast Mexico. Ciencia UANL, 6(3): 360-365.

Zhou P, Luukkanen O, Tokola T, et al. 2008. Effect of vegetation cover on soil erosion in a mountainous watershed. Catena, 75: 319-325. 